\title{
Quantifying the Economic Feasibility of Additive Manufacturing: Simulating Production Lifetimes in the Context of Spare Parts Production
}

\author{
Jyrki Savolainen and Mikael Collan
}

\section{INTRODUCTION}

As discussed already in the preceding chapters, additive manufacturing (AM) refers to the transferring of digital blueprints into a tangible objects by $3 \mathrm{D}$-printing $[1,2]$. The economic feasibility of additive manufacturing has been, and still is a question of discussion-however, it has become clear that there are a number of specific instances, where additive manufacturing is able to create benefits that overweigh the involved costs. Specifically in cases, where the to-be-manufactured items, typically parts, require difficult to construct geometries, or that would benefit from having cavities within the geometry, additive manufacturing has already proven to carry considerable benefits. Discussion in the previous academic

J. Savolainen $(\bowtie) \bullet$ M. Collan

LUT University, Lappeenranta, Finland

e-mail: jyrki.savolainen@lut.fi; mikael.collan@lut.fi

(C) The Author(s) 2020

M. Collan, K.-E. Michelsen (eds.), Technical, Economic and Societal

Effects of Manufacturing 4.0,

https://doi.org/10.1007/978-3-030-46103-4_8 
literature has not been very precise about quantifying the economics of additive manufacturing and mostly the discussion has been done on a project-based level, where feasibility of additive manufacturing has been looked at from the point of view of the said projects [3-5]. Industrial contexts that have been studied in this vein include hearing aid production [6], chocolate [7], and military aviation [8].

All in all, the situation is quite unsatisfactory from the point of view of better understanding the types of things that drive the economic feasibility of additive manufacturing in general and there seems to be as such a rather clear need for straightforward quantitative analyses that would illustrate what kind of potential and/or expectations one can make with regards to the economics of additive manufacturing methods, perhaps not alone, but as parts of manufacturing systems. Discussion of additive manufacturing economics has mostly happened within the context of talking about business models around additive manufacturing and more broadly manufacturing 4.0-this is also reflected above in the chapter of this book that concentrates on the business models.

In this chapter we look at the quantification of the feasibility and the economics of additive manufacturing from the point of view of spare parts manufacturing that is we use it as the underlying context. The production of spare parts for technically high-end industries such as the automotive and the aerospace industry $[8-11]$ is something that has already been found economically viable, therefore it constitutes a good ground for quantitative illustrations. Spare parts manufacturing is interesting also from the point of view that the spare parts business has some distinct characteristics, which make it fit especially well with additive manufacturing: there is a need for reducing lead times, for minimizing the supplier's inventory [12], and there is also the issue of extending the time original equipment manufacturers (OEM) are able to offer spare parts support $[13,14]$. Typically the demand of spare parts is variable on the very short time frame and the demand trend also changes with the lifecycle of the items for which the parts designed, this is why manufacturers try to rigorously minimize the spare part stock at hand, while they must be able to deliver parts quickly on-demand. The speed requirement is accentuated in situations where the parts-availability is contracted until years ahead.

Traditionally, spare parts inventory-issues are resolved by aggregating demand and serving customers from typically country-specific stocks. As spare parts, for example, for production equipment may be tailor-made for customers and OEM-stock of these parts must be constantly held, this 
Table 1 Robust evaluation of economic and manufacturing issues regarding additive and traditional manufacturing (based on previous literature)

\begin{tabular}{lll}
\hline Product/Part & Additive manufacturing & $\begin{array}{l}\text { Traditional } \\
\text { manufacturing }\end{array}$ \\
\hline $\begin{array}{l}\text { Market segment (type) } \\
\text { Market potential }\end{array}$ & Niche & Mass \\
Market volumes & Low & High \\
Market demand pattern & Medium to high & Low to high \\
Product customization need & Stable/uncertain/unitary & Stable/uncertain \\
Product's value added (to customer) & High & Low \\
Product value versus transport cost & Low & Low \\
$\begin{array}{l}\text { Product size } \\
\text { Product's geometric complexity }\end{array}$ & Small & High \\
Product's structural integrity & High & Large \\
requirements & High & Low \\
Manufacturing automation (today) & Low & Maximum \\
Manufacturing phases & $\geq 2$ & High \\
Raw material needed to create a & 1 & 1 \\
product, n & & $\geq 2$ \\
Raw material's machinability & Low & \\
Raw material cost & High & High \\
Raw material origin & Synthetic & Low \\
Raw material's natural form & Powder & Organic \\
Raw material's ratio of material & High & Solid \\
removal (solid only) & & Low \\
\hline
\end{tabular}

may mean that the total inventory holding costs of spare parts may be considerably high. Another issue is that when centralized inventories are used, the cost of logistics that is, transportation of spare parts, may be very high, sometimes even higher than the cost of a single part. Table 1 provides a general summary of issues related to the economics and manufacturing of spare parts and products that have been considered important from the point of view of manufacturing economics in the previous literature and for each of which a robust (linguistic) evaluation has been given (also based on previous literature) both for additive and for traditional manufacturing.

The list of issues and the "evaluations", presented in Table 1, has been collected and summarized from $[13,15-25]$ and makes for a rather comprehensive summary of the things that affect the economies of additive manufacturing in the context of spare parts manufacturing, however the list is most likely relevant also beyond this context. To explore the 
combination of item qualities, which make them economically viable for AM-technology, we derive and use a simulation model that numericallyinstead of qualitatively (see Table 1) - deals with the critically important variables. The type of analysis is of comparative type as, parallel to AM-scenario, also the cost of conventional manufacturing is calculated. Assuming an item's quality to be independent on the way that how it is made, it is highly unlikely that an endogenous transition to this new technology would realize without any of the underlying economic drivers, which we now quantify in this research.

With the results from the model we take a stab at the discussion about the "bigger picture" of the economics of additive manufacturing in the context of spare parts manufacturing. The picture we paint is formed taking into consideration the uncertainty and the limited information surrounding the studied six spare part lifetime strategies. The number of previous studies, where simulation analysis is used in this context (economics of additive manufacturing) is small. An exception to the rule is the closely connected simulation-based research by [19] provides insight into postponement strategies in the supply chain in connection with additive manufacturing.

To the best of our knowledge, there is no previous research that would explore the feasibility - and the economic space of additive manufacturing in a similar way that is done here-this makes this research novel in this respect. Here we limit our interest on the economic aspects of using additive manufacturing within the "production lifetime" of spare parts products (production)-more specifically we concentrate on the cost of production aspect. We do not take positions with regards to the different technical aspects and refer the reader interested in technical issues to see [4, 20, 26-31]. We omit discussions about business models surrounding and based on additive manufacturing as they are already discussed in detail elsewhere in this book.

The rest of this paper is organized as follows: the following chapter provides a high-level problem description together with the technical details of the simulation model. then the numerical simulation results from the simulation are presented with factor analysis concerning individual variables. These numbers are supported by a detailed discussion on the attained insights within the limits of the simulation. The paper is closed by drawing some conclusions and discussing the results. 


\section{Identified Additive Manufacturing Strategies, the Model Used, and the Simulation Setup}

The managerial decision on what manufacturing technology is chosen for a new manufacturing "project" is not a fixed one in the sense that the answer is always "conventional" or always "additive". The choice depends on the situation-in a case, where there is no existing demand-base calls for flexibility that is, the ability to be able to start small ("niche market") and then expand production later, in case the demand grows. In a case, where the economics are clear from the beginning, with established markets and stable and strong demand, the easiest and perhaps the safest way to go is typically to choose the use of conventional manufacturing methods. In cases where the demand is low and volatile in the starting phase, then grows and stabilizes, and perhaps towards the end of the life-cycle of the product deteriorates and becomes volatile again, one may consider first using additive manufacturing, then switching to conventional and back again at some point. This means that hybrid strategies are possible, and may be the smartest choice. In this vein, for the purposes of this research we identify six possible production strategies discussed in the previous literature on additive manufacturing:

Strategy 1- "Full TDM", where traditional manufacturing methods are used for the whole manufacturing lifecycle. This is the typical case for products with existing and stable demand and the case, when additive manufacturing possibilities do not exist.

Strategy 2-"Full AM", where the production during the whole manufacturing lifecycle is done by using additive manufacturing technologies.

Strategy 3-"End of life AM", where production is started with traditional manufacturing methods and towards the end of life of the product, when demand typically decreases until it disappears, production is changed to additive manufacturing.

Strategy 4-"Bridge", where the production is started with additive manufacturing methods and if (when) it picks up in a way that justifies using traditional (mass) production technologies and the connected investments they are adopted.

Strategy 5-"Bridge + end of life AM", where production is started with additive manufacturing, then moved to traditional manufacturing and again, towards the end of life changed to additive manufacturing. 
Strategy 6- "Other", include more than two production mode switching decisions and therefore does not fall into any of the aforementioned categories.

Now, the goal here is not to test each one of the above strategies separately, by creating a model for them, but to use a numerical simulation to randomly create a large number of "production lifecycles" that exhibit combinations of using AM and TDM during the lifecycle and to see which strategies are manifested in the simulated lifecycles, under what kinds of circumstances, and how often. Practically put, the simulation process to create the production lifecycles is run in the following way for a single lifecycle (scenario):

1. Random values are drawn for the product characteristics from the given variable value ranges (that represent the uncertainty)

2. Month-by-month production-cost arrays for both the additive manufacturing, $\mathrm{c}_{\mathrm{AM}}$, and the conventional manufacturing, $\mathrm{c}_{\mathrm{CM}}$, of the product are calculated. Cumulative values are calculated by using a fixed demand pattern for 300 months (discussed in detail below). For a more analytical description see Appendix A

3 . For each month, we choose the smaller of the two simulated costs $\left[\mathrm{c}_{\mathrm{AM}}, \mathrm{c}_{\mathrm{CM}}\right]$ to arrive at $\mathrm{c}_{\mathrm{OPT}}$ that represents a "theoretically optimal production mode" for each month. By adding the monthly $\mathcal{C}_{\mathrm{OPT}}$ values the cumulative optimal lifetime cost is calculated.

4. The number of switching points is calculated; when $\mathrm{c}_{\mathrm{AM}}(t)<\mathrm{c}_{\mathrm{CM}}(t-1)$, and $\mathrm{c}_{\mathrm{AM}}(t)>\mathrm{c}_{\mathrm{CM}}(t+1)$, or vice versa, and the timing of switching with respect to the product lifecycle is observed (see Appendix B for further details)

Put simply, we let the simulation model estimate the "optimal" use of AM-technology by using a simplistic rule of "switch if the alternative is cheaper" and explore the results to see whether the production mode switches coincide with any of the above-listed strategies.

The "world" that underlies the simulation and to which the switching rule is subject to consists of a single (fixed) demand-scenario. This is also (and obviously) a simplification of reality, because in reality there may be a virtually infinite number of possible demand scenarios - but for the sake of illustration, we limit the realism of the simulation and use only one demand scenario. This scenario is based on the idea that the underlying product is a newly launched product, the demand of which has first a fast 

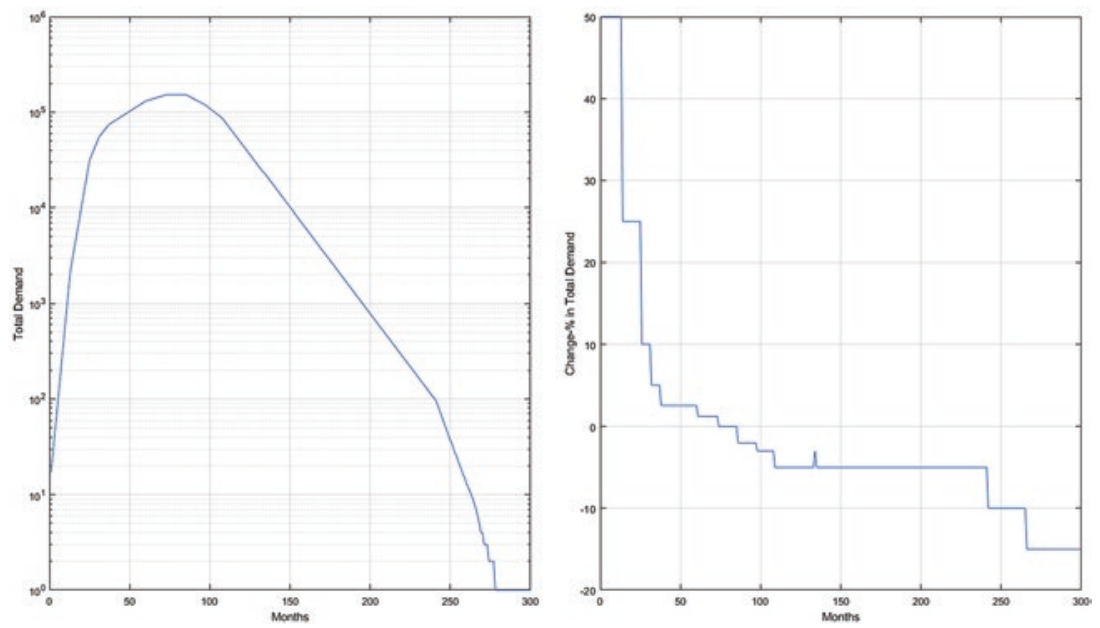

Fig. 1 The demand pattern used, visualized as a function of time. Left: Example of total demand of spare parts plotted on a logarithmic y-scale. Right: Change- $\%$ in demand

positive evolution and that the demand, after having peaked, declines less rapidly. The demand pattern used here is "smooth" and does not include any short-term variance that would in reality be typical of the demand for a product. The demand pattern is visible in Fig. 1.

The rest of "the world" surrounding the product life-time is made of eight variables, see Table 2 , the values of which, together with the demand curve can be used to determine whether the production cost is lower with additive manufacturing or by way of traditional manufacturing. The variables represent issues that have in the literature been identified as important from the point of view of adoption of additive manufacturing-the selection has been made by the authors. To generalize the cost of additive manufacturing is defined as a multiplier of traditional manufacturing unit cost.

In the simulation each scenario (each production situation tested) is randomly generated, by drawing a random value for each one of the input variables. The initial variable value distributions are uniform that is, all values are equally likely for all parameters. After the initial values are drawn the "production" continues month-by-month following the demand curve. What we effectively do is that we run a Monte Carlo simulation 
Table 2 Input variables and their limits, uniform distributions are used

\begin{tabular}{lllll}
\hline Variable & Description & Unit & Min & Max \\
\hline i1 & $\begin{array}{l}\text { Installed base of existing equipment } \\
\text { at } t=0\end{array}$ & pcs & 10 & 1000 \\
i2 & Average part lifetime & months & 6 & 36 \\
i3 & Safety Stock requirement & $-[$ ratio $]$ & 0.01 & 1 \\
i4 & Relative direct cost of part using AM & $-[$ ratio $]$ & 1 & 10 \\
& vs. TDM & $-[\$ / € / £$, etc. $]$ & 10 & 1000 \\
i5 & Cost of part using TDM & pcs & 10 & 5000 \\
i6 & Minimum lot size of TDM & $-[$ ratio $]$ & 0.01 & 0.1 \\
i7 & Relative cost of storing in TDM & $\%$ & 0.01 & 0.1 \\
i8 & Riskless interest rate & & & \\
\hline
\end{tabular}

(MCS) - the number of rounds or "productions" used is 500,000. The resulting input-output pairs are then studied by way of factor analysis (FA) to identify the robust relative importance of each variable for the outcome. As such the results are quite robust and general.

\section{The Simulation Model Used}

As discussed above, the main idea of using a simulation model is to perform a robust comparison of the relative costs of additive manufacturing versus conventional manufacturing and to see whether it is AM or TDM that would be used in the production. In essence, the model calculates the monthly production cost for the both production methods, based on selected input variable values and a fixed demand curve. At any point of time during the simulated production life-span, the preferred production mode is explicitly given as:

$$
\begin{aligned}
& \mathbf{I F}[\text { current AM cost }]<[\text { current TDM cost }] \\
&: \text { THEN use AM ELSE use TDM. }
\end{aligned}
$$

We assume that the demand is fulfilled instantly when AM is used, whereas in the case of TDM items must be ordered beforehand-a safety stock requirement ( $i 3)$ is used to buffer the demand in TDM, which increases the total number of spare parts needed (for details see Appendix A). Based on the relative cost of storing (i7) a total yearly inventory cost is calculated, which is then evenly divided to months and used in the monthly 
Table 3 Outputs from the simulation model

\begin{tabular}{lll}
\hline Variable & Description & Unit \\
\hline o1 & Initial mode of production, where 0 = TDM & $0 / 1$ \\
& $\begin{array}{l}\text { and I = AM } \\
\text { o2 }\end{array}$ & Months \\
o3 & Sum of AM months & $N$ \\
o4 & Total number of switching points & $-($ time $)$ \\
o5 & Time of first production mode switch & $-($ time $)$ \\
o6 & Time of the last production mode switch & $0 / 1$ \\
o7 & Final mode of production & $N$ \\
o8 & Product volume & $-[\$ / € / £$, etc. $]$ \\
o9 & TDM total cost & $-[\$ / € / £$, etc. $]$ \\
o10 & AM total cost & $-[\$ / € / £$, etc. $]$ \\
o11 & Absolute cost difference, TDM vs. AM & $\%$ \\
\hline
\end{tabular}

EoL end of life, TDM traditional manufacturing, $B r M$ bridge manufacturing

cost calculation. Riskless interest rate (i8) describes the opportunity cost of having the money invested into product stock. As additional simplification, we assume the production of spare parts to be fully contracted and requiring no capital investment on the production equipment and that there are no restrictions in the availability of the contracted capacity. No obsolescence of stored products is assumed in modeling the TDM cost.

The list of outputs is shown in Table 3. Based on Eq. (1) we count the total number of $A M$ months (o2) for each simulated production lifetime. The information on the number of production mode switches during the simulation is stored in output 03 , outputs $07-011$ are calculated from the simulation results. The focal output of this exploratory research is the costs of AM compared to the costs of TDM over the production lifetime and most importantly whether AM or TDM is used-the technology that is used determines the additive manufacturing profile of the production lifecycle that is compared to the six identified strategies. Also the (expected) cumulative costs for both TDM (08) and AM (09) are calculated for the simulation. To determine the "preferred mode of production" we have:

$$
\begin{gathered}
\text { IF }[\text { cumulative AM cost }]<[\text { cumulative TDM cost }]: \text { THEN select } \\
{[\text { Preferred mode of production }]=\text { AM ELSE TDM }}
\end{gathered}
$$


The first and the last switching point times ( 04 and 05$)$, together with production mode information ( 01 and 06 ) are combined into an insight of switching flexibility. These outputs indicate when, if at all, AM-technology would most likely be used during the production lifetime. For simplicity, we assume that the production mode (AM/TDM) can be changed. Costs and delays and that the inventory carrying costs are not inherited, once the production changes from TDM to AM. We observe that this is a nonrealistic simplification and do not claim that the model gives a fully realistic picture of how switching could happen in the real world, where hysteresis is typically present in switching decisions [32]. We point out that the definitions used for the six reference-strategies are provided in Appendix B.

\section{Simulated Results and Analysis}

The simulated results for the 500,000 production lifecycles were automatically processed according to the rules laid out in Appendix B and matched to the six reference additive manufacturing strategies. The results are visible in Table 4.

Based on the obtained results we are able to summarize some exploratory insights. First, there seems to be potential to extend the lifetime of products with AM-based spare part support-even in situations, where the cost of AM is significantly higher than the cost of TDM (up to $5.76 * \mathrm{x})$ - this is in line with Strategy 3, "End of life AM". Second, Strategy 4 "Bridge"-manufacturing applications are found seem to be viable, when a small installed base of equipment exists. We further note that investing in bridge manufacturing effectively opens the option for end-of-life additive manufacturing. The combination of bridge-and end-of-life manufacturing that is Strategy 5 , is visibly a more prominent manufacturing strategy than bridge-manufacturing alone. Third, high-volume products with reasonably small LOT-sizes that do not have manufacturing or inventory cost disadvantages, seem to stay mass-manufactured that is, Strategy $l$ is strong for products of this type.

Interestingly it seems that also high-volume products can benefit from end-of-life AM that is, Strategy 3 is strong also there. Overall Strategy 3 and end-of-life production is the leading strategy in terms of where additive manufacturing seems feasible. Strategy 2, using additive manufacturing for the whole production life cycle, seems to be marginal in terms of how frequently it is feasible in the context of this study-only $0.12 \%$ of 
Table 4 Results of 500,000 rounds of simulations divided strategy by strategy and mean values for the input variables and for the outputs

\begin{tabular}{|c|c|c|c|c|c|c|}
\hline Mean values & EoL & $T D M$ & $\mathrm{BrM}+\mathrm{EoL}$ & Others & $\mathrm{BrM}$ & Full $A M$ \\
\hline $\begin{array}{l}\text { Sum of AM } \\
\text { months }\end{array}$ & 26.82 & 0.00 & 59.84 & 16.00 & 2.00 & 301.00 \\
\hline $\begin{array}{l}\text { Total Number } \\
\text { of Switches }\end{array}$ & 1.00 & 0.00 & 3.26 & 2.54 & 1.00 & 0.00 \\
\hline $\begin{array}{l}\text { Time of First } \\
\text { Switch }\end{array}$ & 275.18 & $\mathrm{NaN}$ & 4.22 & 265.61 & 3.00 & 0.00 \\
\hline $\begin{array}{l}\text { Time of Last } \\
\text { Switch }\end{array}$ & 275.18 & $\mathrm{NaN}$ & 248.33 & 286.76 & 3.00 & 0.00 \\
\hline $\begin{array}{l}\text { Final mode } \\
(\mathrm{AM}=1 \\
\text { Trad }=0)\end{array}$ & 1.00 & 0.00 & 1.00 & 0.33 & 0.00 & 1.00 \\
\hline $\begin{array}{l}\text { Time of lst } \\
\text { Switch (cumul.) }\end{array}$ & $\mathrm{NaN}$ & $\mathrm{NaN}$ & 5.73 & 5.09 & 3.94 & $\mathrm{NaN}$ \\
\hline Volume, $n$ & 32.83 & 32.21 & 12.21 & 26.76 & 3.50 & 29.74 \\
\hline $\begin{array}{l}\text { TDM-cost, } \\
{ }^{a} 1000 \text { unit of } \\
\text { money }\end{array}$ & $16,742.15$ & $16,422.77$ & 6206.34 & $13,668.80$ & 1749.90 & $15,371.64$ \\
\hline $\begin{array}{l}\text { AM-cost, }{ }^{\mathrm{a}} 1000 \\
\text { unit of money }\end{array}$ & $83,355.06$ & $107,873.65$ & 8904.56 & $60,140.40$ & 4724.97 & $15,219.94$ \\
\hline $\begin{array}{l}\text { Diff AM vs. } \\
\text { TDM, a } 1000 \\
\text { unit of money }\end{array}$ & $66,612.91$ & $91,450.88$ & 2698.22 & $46,471.60$ & 2975.06 & -151.70 \\
\hline $\begin{array}{l}\text { Diff-\% AM vs. } \\
\text { TDM }\end{array}$ & 4.14 & 5.59 & 1.36 & 3.51 & 3.69 & -0.01 \\
\hline
\end{tabular}

EoL end of life, $T D M$ traditional manufacturing, $B r M$ bridge manufacturing

Bolded numbers indicate the most significant input variables based on the factor analysis

outcomes reflected this strategy. In these cases the cost of AM very close to the cost of TDM.

To further study the flexibility to switch the production mode, some key results are illustrated in Fig. 2. A great majority of the simulated production lifecycles have between zero and two production mode changes $(96.87 \%)$ - we feel that this shows that the simulation model is in this respect quite realistic. The remaining Strategy 6 that is, "other" scenarios represent only $3.13 \%$ of the outcomes and seem to have an unrealistic average of 18 production mode changes, where outliers have even many tens of changes - as discussed above, this is a feature of the simulation structure and can be explained by the fact that issues such as hysteresis are not considered. The first transition from AM to TDM (or vice versa) 

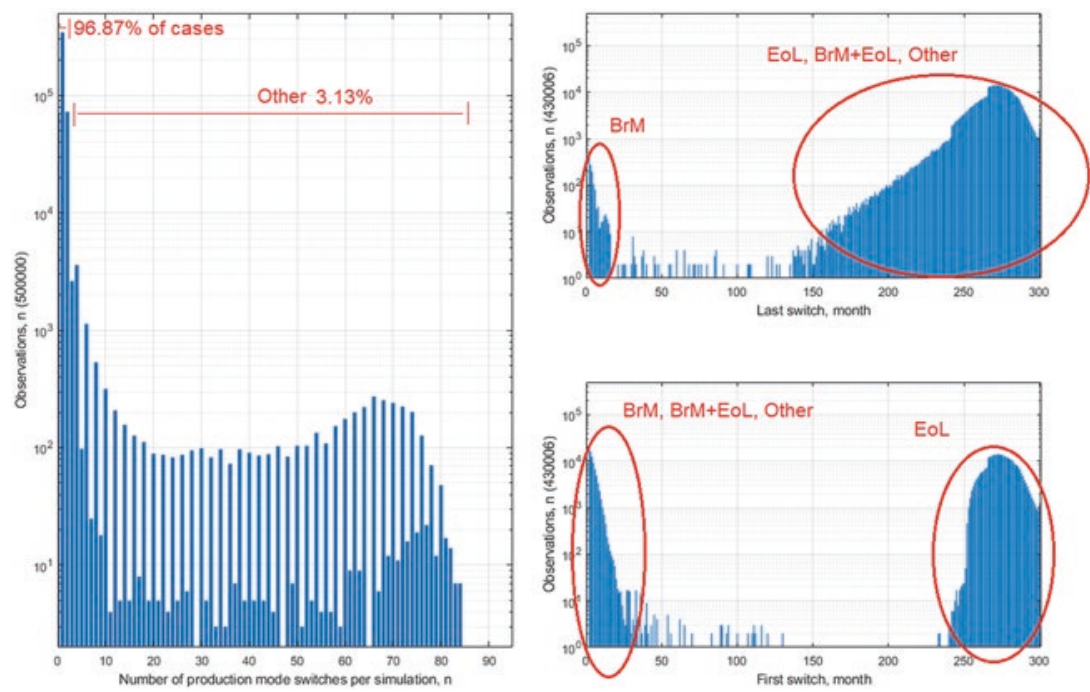

Fig. 2 Histogram representation of production-mode changes from the 500,000 simulation rounds. Observe that the y-axes are logarithmic. Left: \# of mode changes per simulation. Upper right: Timing of the first change. Lower right: Time of the last change

occurs either in the start, or in the end of product lifetime. The timing of the last change exhibits an interesting pattern that suggests that the timing of the final production mode change in Strategy 3 (End-of-life AM) depends on product-specific characteristics and the switch time ranges from $~ 150$ to 300 months and averaging for Strategy 3 at 274 months $(\sim 8.5 \%$ of life left) and for Strategy 5 (Bridge + end-of-life) at 247 months $(\sim 17.5 \%$ life left $)$. The bridge-manufacturing period lasts on average only four months ( $1.5 \%$ of life). These simulated change-times are dependent on the inputs and especially on the demand curve, so they cannot be generalized and are quoted here for illustration only (Table 5).

Factor analysis of the results reveals that some included input variables have only a small effect on the economic feasibility of AM (parts durability, safety stock ratio, TDM unit cost, and inventory costs). On the other hand the relationship between the cost of AM and the cost of TDM and the size of the installed machine base (production volume) seem to be important issues from the point of view of AM feasibility. These are, however, only 
Table 5 Factor analysis of the input variables

\begin{tabular}{lllllll}
\hline & $\begin{array}{l}\text { Strategy 1 } \\
\text { Full TDM }\end{array}$ & $\begin{array}{l}\text { Strategy } 2 \\
\text { Full AM }\end{array}$ & $\begin{array}{l}\text { Strategy } \\
3 \text { EoL }\end{array}$ & $\begin{array}{l}\text { Strategy } \\
\text { BrM }\end{array}$ & $\begin{array}{l}\text { Strategy } 5 \\
\text { BrM EoL }\end{array}$ & $\begin{array}{l}\text { Strategy 6 } \\
\text { Other }\end{array}$ \\
\hline $\begin{array}{l}\text { i1 Installed } \\
\text { base }\end{array}$ & 0.043 & -0.044 & -0.086 & 0.997 & 0.997 & -0.038 \\
$\begin{array}{l}\text { i2 Durability, } \\
\text { months }\end{array}$ & -0.036 & -0.015 & 0.076 & 0.069 & 0.156 & 0.021 \\
$\begin{array}{l}\text { i3 Safety stock } \\
\text { ratio }\end{array}$ & -0.01 & 0.351 & 0.001 & -0.206 & -0.013 & -0.014 \\
$\begin{array}{l}\text { i4 AM cost } \\
\text { multiplier }\end{array}$ & 0.095 & 0.997 & 0.997 & -0.51 & -0.481 & 0.916 \\
$\begin{array}{l}\text { i5 TDM Unit } \\
\text { Cost }\end{array}$ & -0.001 & 0.044 & 0.001 & 0.048 & 0.008 & 0 \\
$\begin{array}{l}\text { i6 TDM } \\
\begin{array}{l}\text { LOT-size } \\
\text { i7 TDM }\end{array}\end{array}$ & $\mathbf{0 . 9 9 7}$ & 0.05 & 0.134 & 0.177 & 0.143 & -0.273 \\
$\begin{array}{l}\text { Storage cost } \\
\text { ratio }\end{array}$ & -0.223 & 0.239 & 0.136 & 0.232 & 0.103 & -0.108 \\
$\begin{array}{l}\text { 88 Riskless } \\
\text { interest Rate }\end{array}$ & 0.001 & 0.285 & 0.002 & -0.034 & -0.005 & 0.009 \\
\hline
\end{tabular}

EoL end of life, TDM traditional manufacturing, $B r M$ bridge manufacturing

Value-range is $[-1,-1]$, where values close to 1 and -1 indicate a strong relationship (direct or "inverse") with the Strategy. Inverse means here that large negative values mean that the small variable values link to the specific Strategy. Strong relationships bolded, important relationships in italics

exploratory and illustrative results that are the results of the assumptions used in the simulation model.

\section{Summary, Conclusions, and Discussion}

This chapter has discussed the economic viability and feasibility of additive manufacturing as a part of the production lifecycle of spare parts production. A simulation model was used to randomly create a large number of different possible production lifecycles that were, with the help of a stylized demand curve, analyzed for, when under the assumed circumstances production would be made with additive manufacturing and alternatively with traditional manufacturing methods. The resulting lifecycle patterns of AM and TDM use or manufacturing strategies were compared to six, from the literature identified strategies, and the relative frequency of the 
Table 6 Main findings for the six production strategies with frequency in the simulations

\begin{tabular}{|c|c|}
\hline Production strategy & Strategy details, relative frequency in simulations \\
\hline $\begin{array}{l}\text { Strategy 1-“Full } \\
\text { TDM" }\end{array}$ & $\begin{array}{l}\text { The main strategy for high-volume, cheap-to-store products } \\
\text { with reasonably small LOT-sizes; } 14 \% \text { of the cases }\end{array}$ \\
\hline Strategy 2-"Full AM" & $\begin{array}{l}\text { Strategy seems to be feasible only, when AM manufacturing } \\
\text { costs are equal to the costs of TDM; } 0.12 \% \text { of the cases }\end{array}$ \\
\hline $\begin{array}{l}\text { Strategy 3-"End of life } \\
\text { AM" }\end{array}$ & $\begin{array}{l}\text { Strategy for parts with relatively large LOT-sizes that are too } \\
\text { expensive for large scale AM production. With declining } \\
\text { demand, the costs of holding inventories outweigh the costs of } \\
\text { AM-production; } 68.5 \% \text { of the cases }\end{array}$ \\
\hline Strategy 4-“Bridge" & $\begin{array}{l}\text { Strategy for niche-volume parts with very high durability and } \\
\text { large LOT-sizes. AM is feasible for a short period of time after } \\
\text { the product launch; } 0.23 \% \text { of the cases }\end{array}$ \\
\hline Strategy & Strategy for small volume, highly durable parts, which would \\
\hline $\begin{array}{l}\text { 5-"Bridge + End-of- } \\
\text { Life AM" }\end{array}$ & $\begin{array}{l}\text { require large LOT-sizes in mass production, but are relatively } \\
\text { cheap to manufacture with AM; } 14 \% \text { of the cases }\end{array}$ \\
\hline Strategy 6-"Other" & $\begin{array}{l}\text { Strategies for small to medium volume parts that are both } \\
\text { cheap to produce with AM and have a small LOT-size in TDM, } \\
\text { "the rest of the strategies"; } 3.13 \% \text { of the cases }\end{array}$ \\
\hline
\end{tabular}

six strategies was determined. Table 6 lists the main findings for each of the six strategies.

The findings presented above are in line with what can be found from the literature and quite strongly reinforce the notion that end-of-life use of additive manufacturing is an economically viable and feasible strategy to adopt the use of additive manufacturing in the production lifecycle of spare parts. Factor analysis was used to find the most important variables from the point of view of each one of the strategies - the main finding was that the relationship between the cost of AM and the cost of TDM and the size of the installed machine base (production volume) seem to be important issues from the point of view of AM feasibility.

This research is exploratory and has numerous limitations-the results are guided by the initial selection of variables, their value ranges, and the fixed demand pattern used. The simulation was performed purely with a simple cost point-of-view in mind and without taking into account other factors. Issues such as design benefits and other added value from AM, market dynamics, hysteresis, and many other possibly important issues were left outside the scope of this research. This being said, the research presented here is among the first attempts to quantify 
the feasibility of additive manufacturing in production lifecycles and as such is a contribution to what we know about the economics of additive manufacturing.

\section{Appendix A}

DEMAND MODELING/Actual and safety stock demand for spare parts at time $t$ :

[Demand actual, $t]=[$ Installed base, $n] \times[$ Part durability, months $]$

$[$ Demand stock, $t]=[$ Demand actual, $t] \times[$ Safety stock ratio $]$

- $[$ Demand TOTAL, $t]=[$ Demand actual, $t]+[$ Demand stock, $t]$

COST MODELING/Cost of conventional manufacturing:

Total cost of conventional manufacturing, $\mathrm{C}_{\mathrm{CM}}$, is the sum of production cost, stock holding cost and the opportunity cost of holding the stock:

$\mathrm{C}_{\mathrm{CM}, \mathrm{p}}=[$ Production Lot-size, $n] \times[$ Demand TOTAL,$t] \times[$ Production cost $\mathrm{CM}, \mathrm{EUR} / \mathrm{pc}]$

$\mathrm{C}_{\mathrm{CM}, \mathrm{s}}=[$ Stock size, $\mathrm{pcs}] \times[$ Stock holding cost, $\mathrm{EUR} / \mathrm{pc}]+[$ Opportunity cost, EUR], where

[Opportunity cost, EUR $]=[$ Production cost CM, EUR/pc $] \times[$ Stock holding cost, EUR/pc] $\times$ [Riskless Interest Rate]

- $\mathrm{C}_{\mathrm{CM}}=([$ Production Lot-size, $n] \times[$ Demand TOTAL, $t] \times[$ Production cost CM, EUR/pc $])+([$ Stock size, $\mathrm{pcs}] \times[$ Stock holding cost, EUR/ $\mathrm{pc}])+([$ Production cost CM, EUR/pc] $\times[$ Stock holding cost, EUR/ pc] $\times$ [Riskless Interest Rate $])$

COST MODELING/Cost of additional manufacturing:

Total cost of additive manufacturing does not include the costs associated with production lot sizes and stocks:

$\mathrm{C}_{\mathrm{AM}}=[$ Demand TOTAL, $t] \times[$ Production cost, $\mathrm{AM}]$

\section{Appendix B}

Analytical definitions of the six production strategies

Strategy 1/2-"Full AM/TDM": 
$\mathbf{I F}[$ Number of swithces $]=0$

AND $[$ Final production mode $]=[\mathrm{AM}](\mathrm{TDM})$

$\mathbf{A N D}[$ Initial production mode $]=[\mathrm{AM}](\mathrm{TDM})$

Strategy 3-"End-of-Life AM":

$$
\begin{aligned}
\mathbf{I F}[\text { Number of switches }] & =1 \\
\mathbf{A N D}[\text { Final production mode }] & =[\mathrm{AM}] \\
\mathbf{A N D}[\text { Initial production mode }] & =[\mathrm{TDM}]
\end{aligned}
$$

Strategy 4-"Bridge Manufacturing":

$$
\text { IF }[\text { Number of switches }]=1
$$

AND $[$ Final production mode $]=[\mathrm{TDM}]$

AND $[$ Initial production mode $]=[\mathrm{AM}]$

Strategy 5-“Bridge and End-of-Life manufacturing":

$$
\text { IF }[\text { Number of switches }]=2
$$

AND [Initial production mode $]=[\mathrm{AM}]$

AND $[$ Final production mode $]=[\mathrm{AM}]$

Strategy 6- "The remaining production strategies-others", are derived in two parts: (a) scenarios, where the number of production mode changes is greater than two; and (b) cases that have two production mode changes, but are not Bridge + End-of-life (AM start and end):

$$
\text { IF }[\text { Number of switches }]>2
$$

\section{and}

$$
\text { IF }[\text { Number of switches }]=2
$$




$$
\begin{aligned}
& \text { AND }[\text { Initial production mode }]=[\mathrm{TDM}] \\
& \mathbf{A N D}[\text { Final production mode }]=[\mathrm{TDM}]
\end{aligned}
$$

\section{REFERENCES}

1. T. Rayna and L. Striukova, "From rapid prototyping to home fabrication: How 3D printing is changing business model innovation," Technol. Forecast. Soc. Change, vol. 102, pp. 214-224, 2016.

2. J. Holmström, M. Holweg, S. H. Khajavi, and J. Partanen, "The direct digital manufacturing (r)evolution: definition of a research agenda," Oper. Manag. Res., vol. 9, no. 1-2, pp. 1-10, 2016.

3. M. Attaran, "The rise of 3-D printing: The advantages of additive manufacturing over traditional manufacturing," Bus. Horiz., vol. 60, no. 5, pp. 677-688, 2017.

4. T. D. Ngo, A. Kashani, G. Imbalzano, K. T. Q. Nguyen, and D. Hui, “Additive manufacturing (3D printing): A review of materials, methods, applications and challenges," Compos. Part B Eng., vol. 143, pp. 172-196, 2018.

5. V. Petrovic, J. Vicente Haro Gonzalez, O. Jordá Ferrando, J. Delgado Gordillo, J. Ramon Blasco Puchades, and L. Portoles Grinan, "Additive layered manufacturing: Sectors of industrial application shown through case studies," Int. J. Prod. Res., vol. 49, no. 4, pp. 1061-1079, 2011.

6. C. G. Sandström, "The non-disruptive emergence of an ecosystem for 3D Printing - Insights from the hearing aid industry's transition 1989-2008," Technol. Forecast. Soc. Change, vol. 102, pp. 160-168, 2016.

7. F. Jia, X. Wang, N. Mustafee, and L. Hao, "Investigating the feasibility of supply chain-centric business models in 3D chocolate printing: A simulation study," Technol. Forecast. Soc. Change, vol. 102, pp. 202-213, 2016.

8. S. H. Khajavi, J. Partanen, and J. Holmström, "Additive manufacturing in the spare parts supply chain," Comput. Ind., vol. 65, pp. 50-63, 2014.

9. J. Holmström, J. Partanen, J. Tuomi, and M. Walter, "Rapid manufacturing in the spare parts supply chain: Alternative approaches to capacity deployment," J. Manuf. Technol. Manag., vol. 21, no. 6, pp. 687-697, 2010.

10. L. F. C. S. Durão, A. Christ, R. Anderl, K. Schützer, and E. Zancul, "Distributed Manufacturing of Spare Parts Based on Additive Manufacturing: Use Cases and Technical Aspects," Procedia CIRP, vol. 57, no. January 2017, pp. 704-709, 2016.

11. M. Savastano, C. Amendola, F. D'Ascenzo, and E. Massaroni, "3-D Printing in the Spare Parts Supply Chain: An Explorative Study in the Automotive Industry," in Lecture Notes in Information Systems and Organisation, vol. $18,2016$. 
12. S. Ford and M. Despeisse, "Additive manufacturing and sustainability: an exploratory study of the advantages and challenges," J. Clean. Prod., vol. 137, pp. 1573-1587, 2016.

13. G. Manogharan, R. A. Wysk, and O. L. A. Harrysson, "Additive manufacturingintegrated hybrid manufacturing and subtractive processes: Economic model and analysis," Int. J. Comput. Integr. Manuf., vol. 29, no. 5, pp. 473-488, 2016.

14. M. Gebler, A. J. M. Schoot Uiterkamp, and C. Visser, "A global sustainability perspective on 3D printing technologies," Energy Policy, vol. 74, no. C, pp. 158-167, 2014.

15. C. Weller, R. Kleer, and F. T. Piller, "Economic implications of 3D printing: Market structure models in light of additive manufacturing revisited," Int. J. Prod. Econ., vol. 164, pp. 43-56, 2015.

16. M. Matsumoto, S. Yang, K. Martinsen, and Y. Kainuma, "Trends and research challenges in remanufacturing," Int. J. Precis. Eng. Manuf. Technol., vol. 3, no. 1, pp. 129-142, 2016.

17. B. Berman, "3-D printing: The new industrial revolution," Bus. Horiz., vol. 55 , no. 2, pp. 155-162, 2012.

18. J. P. J. de Jong and E. de Bruijn, "Innovation Lessons From 3-D Printing," MIT Sloan Manag. Rev., vol. 54, no. 2, pp. 43-52, 2013.

19. J. Minguella-Canela et al., "Comparison of production strategies and degree of postponement when incorporating additive manufacturing to product supply chains," Procedia Manuf., vol. 13, pp. 754-761, 2017.

20. M. Bogers, R. Hadar, and A. Bilberg, "Additive manufacturing for consumercentric business models: Implications for supply chains in consumer goods manufacturing," Technol. Forecast. Soc. Change, vol. 102, pp. 225-239, 2016.

21. M. Rehnberg and S. Ponte, "From smiling to smirking? 3D printing, upgrading and the restructuring of global value chains," Glob. Networks, vol. 18, no. 1 , pp. 57-80, 2018.

22. A. Laplume, B. Petersen, and J. M. Pearce, "Global value chains from a 3D printing perspective," J. Int. Bus. Stud., vol. 47, no. 5, pp. 595-609, 2016.

23. M. J. Ryan et al., "3D printing the future : scenarios for supply chains reviewed," Int. J. Phys. Distrib. Logist. Manag., vol. 47, no. 10, pp. 992-1014, 2017.

24. B. P. Conner et al., "Making sense of 3-D printing: Creating a map of additive manufacturing products and services," Addit. Manuf., vol. 1-4, pp. 64-76, Oct. 2014.

25. Wohlers, "Additive Manufacturing Technology Roadmap for Australia," 2011.

26. T. Caffrey and T. Wohlers, "An Additive Manufacturing Update," Appl. Des., no. May, pp. 27-29, 2016.

27. K. V. Wong and A. Hernandez, "A Review of Additive Manufacturing," ISRN Mech. Eng., pp. 1-10, 2012. 
28. I. Gibson, D. W. D. W. Rosen, and B. Stucker, Additive Manufacturing Technologies: Rapid Prototyping to Direct Digital Manufacturing. Springer, 2009.

29. T. Wohlers and T. Gornet, "History of additive manufacturing," Woblers Rep. 2014 , p. 34, 2014.

30. W. Gao et al., "The status, challenges, and future of additive manufacturing in engineering," Comput. Des., vol. 69, pp. 65-89, Dec. 2015.

31. H.-J. Steenhuis and L. Pretorius, "Consumer additive manufacturing or 3D printing adoption: an exploratory study," J. Manuf. Technol. Manag., vol. 27, no. 7 , pp. 990-1012, 2016.

32. A. K. Dixit, "Investment and Hysteresis," J. Econ. Perspect., vol. 6, no. 1, pp. 107-132, 1992.

Open Access This chapter is licensed under the terms of the Creative Commons Attribution 4.0 International License (http://creativecommons.org/licenses/ by $/ 4.0 /$ ), which permits use, sharing, adaptation, distribution and reproduction in any medium or format, as long as you give appropriate credit to the original author(s) and the source, provide a link to the Creative Commons licence and indicate if changes were made.

The images or other third party material in this chapter are included in the chapter's Creative Commons licence, unless indicated otherwise in a credit line to the material. If material is not included in the chapter's Creative Commons licence and your intended use is not permitted by statutory regulation or exceeds the permitted use, you will need to obtain permission directly from the copyright holder.

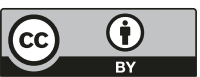

